\title{
Comparison of particle swarm optimization and firefly algorithm in parameter estimation of Lotka-Volterra
}

Cite as: AIP Conference Proceedings 2268, 050008 (2020); https://doi.org/10.1063/5.0017245

Published Online: 17 September 2020

\section{Windarto Windarto, and Eridani Eridani}

\section{ARTICLES YOU MAY BE INTERESTED IN}

On modification and application of Lotka-Volterra competition model AIP Conference Proceedings 2268, 050007 (2020); https://doi.org/10.1063/5.0017242

Stability analysis of mathematical model of virus therapy and chemotherapy for cancer AIP Conference Proceedings 2268, 050005 (2020); https://doi.org/10.1063/5.0017021

On the numerical solutions of a one-dimensional heat equation: Spectral and Crank Nicolson method

AIP Conference Proceedings 2268, 050006 (2020); https://doi.org/10.1063/5.0017131

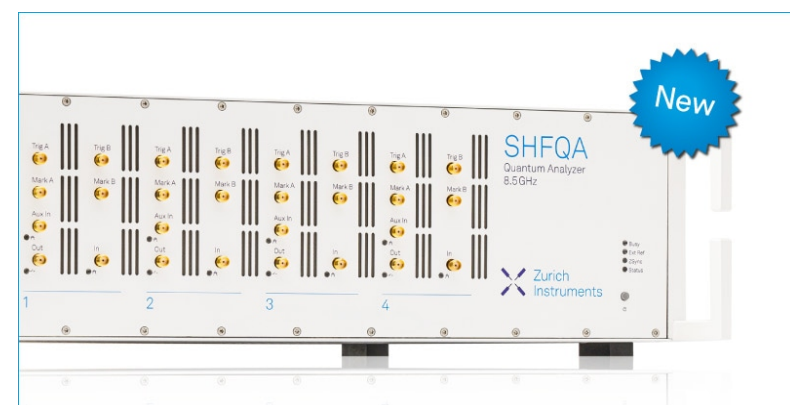
\section{3/5.0017131

Your Qubits. Measured.

Meet the next generation of quantum analyzers

- Readout for up to 64 qubits

- Operation at up to $8.5 \mathrm{GHz}$, mixer-calibration-free

- Signal optimization with minimal latency

\section{Find out more}

Zurich

Instruments 


\title{
Comparison of Particle Swarm Optimization and Firefly Algorithm in Parameter Estimation of Lotka-Volterra
}

\author{
Windarto Windarto ${ }^{\text {a) }}$ and Eridani Eridani \\ Department of Mathematics, Faculty of Science and Technology, Universitas Airlangga, Indonesia
}

${ }^{\text {a)Corresponding author: windarto@fst.unair.ac.id }}$

\begin{abstract}
Lotka-Volterra competition model has been applied in life sciences including competition between species, predicting the Aeromonas hydrophila growth on fish surface. The competition model also has been used in social sciences, including competition in the Korean stock market and competition between two types of bank, namely commercial bank and rural bank in Indonesia. It is well-known that the analytical solution of the Lotka-Volterra is unknown. Here gradientbase methods such as Newton method and Levenberg-Marquardt are difficult to be implemented to estimate paramaters of the model. In order to estimate parameters in the model, one need to use heuristic method such as genetic algorithm, particle swarm optimization, firefly algorithm or other heuristic methods. In this paper, we compared performance of particle swarm optimization and firefly algorithm in parameter estimation of Lotka-Volterra type competition model. Here we used the profit data of commercial bank and rural bank, where the data cited from literature. We found the mean absolute percentage error (MAPE) of firefly algorithm is a little bit smaller than the error of particle swarm optimization method. We also found variance of the error of firefly algorithm is lower than the particle swarm optimization method. Hence, for parameter estimation of Lotka-Volterra competition model, firefly algorithm is more beneficial than the particle swarm optimization method.
\end{abstract}

Keywords: particle swarm optimization, firefly algorithm, parameter estimation, competition model

\section{INTRODUCTION}

In general, a mathematical model contains one or more parameters. Many mathematical models are represented either in the form of a non-linear differential equation or in the form of systems of non-linear differential equations. Hence the exact solutions of the mathematical models could not be determined. As a result, parameter values in the model cannot or are difficult to determine using standard optimization methods such as the Newton method, the Levenberg- Marquardt method and the steepest descent method. In addition, the gradient-based methods typically converge to a local optimum solution [1]. In this condition, one can use heuristic methods such as genetic algorithms, particle swarm optimization, or firefly algorithms to obtain parameter values from a system of nonlinear differential equations $[2,3]$.

The Lotka-Volterra competition mathematical model is widely applied in the field of biological sciences, includ- ing inter-species competition and prediction of Aeromonas hydrophila growth on surface of fish during the refrigerated storage [4]. The competition model has also been utilized in social sciences, including competition of the Korean stock market [5], retail industry competition in Taiwan [6], retailing formats competition [7] and competition between com- mercial banks and rural banks in Indonesia [8]. The competition model is a system of nonlinear differential equations. Hence the analytic solution of the model is unknown.

Like genetic algorithms, particle swarm optimization and firefly algorithms are bio-inspired optimization meth- ods. Basically, the particle swarm optimization method is a continuous optimization method. Moreover, the particle Swarm Optimization method has been applied to combinatorial optimization problems including scheduling problems [9, 10], travelling salesman problems [11], flow shop [12], and vehicle routing problems [13]. Firefly 
algorithm also has been applied to many areas including design optimization of a robotic gripper [14], modelling and study of SSSC compensator [15] and optimization design of FIR digital filter [16].

Some researchers performed a performance comparison of particle swarm optimization and firefly algorithm. Palmieri et al. analyzed performance of particle swarm optimization and firefly algorithm in terms of total energy used by the robots to finished an assignment [17]. Hussain and Jenkins compared the methods for system identifica- tion with various types of nonlinear systems [18]. Farzana and Mahadevan compared performance of the methods on congestion management of deregulated power market [19]. In this article, we compare performance of particle swarm optimization and firefly algorithm in parameter estimation of Lotka-Volterra type competition model.

We organized this paper as follows. In section 2 we briefly presents particle swarm optimization and firefly algorithm. We present performance comparison of the methods in parameter estimation of Lotka-Volterra competition model in section 3. Finally, we draw some conclusions in the last section.

\section{PARTICLE SWARM OPTIMIZATION AND FIREFLY ALGORITHM}

Particle swarm optimization (PSO) is an optimization method inspired from the behavior of birds in a swarm. In PSO method, value of a solution is represented by position of a particle. PSO procedure consists of following main steps:

(1) Generate initial solutions (initial positions) and initial velocities.

(2) Fitness evaluation of every particle.

(3) Renew the individual best solution (pbest particle) and the global best solution (gbest particle).

(4) Renew velocity (v) and position (x) of every particle.

The PSO procedure is repeated until a termination condition is achieved.

In PSO method, particle velocity update is performed by using the following equation

$$
v_{j}(k+1)=w v_{j}(k)+c_{1} r_{1}\left(p_{j}(k)-x_{j}(k)\right)+c_{2} r_{2}\left(g(k)-x_{j}(k)\right), j=1,2, \ldots, n p .
$$

Here $v_{j}(k)$ and $x_{j}(k)$ are the $\mathrm{j}$-th particle velocity and particle position respectively, while $p_{j}(k)$ and $g(k)$ are individual best particle and global best particle at $\mathrm{k}$ iteration. In eq. (1), $w, c_{1}$ and $c_{2}$ are initial weight parameter, individual cognitive parameter and social cognitive parameter respectively. Here $r_{1}$ and $r_{2}$ are random numbers between zero and one with uniform distribution. The typical values of $w, c_{1}$ and $c_{2}$ are $w=1, c_{1}=c_{2}=2$.2. Position update is performed by using the following equation

$$
x_{j}(k+1)=x_{j}(k)+x_{j}(k+1) \text {. }
$$

Firefly algorithm is an optimization method inspired from fireflies flashing behaviour, where a firefly moves to another brighter firefly. In the algorithm, a solution is represented by a firefly position. Firefly algorithm consists of three main steps namely generate initial solutions, evaluate fitness of every solution and update the solutions until some termination condition is reached. In a minimization problem of a function $\mathrm{f}$, the main update of firefly position of $\mathrm{xi}$ and $\mathrm{x} \mathrm{j}$ where $\mathrm{f}(\mathrm{x} \mathrm{j})<\mathrm{f}(\mathrm{xi})$, is given by the following equation

$$
x_{j}(k+1)=x_{i}(k)+\beta \exp \left(-\gamma r_{i j}^{2}\right)\left(x_{i}(k)-x_{j}(k)\right)+\alpha(k) \varepsilon(k) .
$$

Here $r_{i j}$ is distance between position $x_{i}$ and $x_{j}$, while $\alpha(k)$ is a parameter controlling the step size at the $\mathrm{k}$ iteration and $\varepsilon(k)$ is a random vector with Gaussion or other distribution at the k iteration. In eq. (3) $\beta$ and $\gamma$ are scalar parameters.

Premature convergence is commonly problem in implementation of a heuristic method including in the PSO method and the firefly algorithm. In order to obtain the best solution from PSO and FA, both algorithm should be applied many times. In the next section, we compared performance comparison of the methods in parameter estimation of a dynamical system model, namely the Lotka-Volterra competition model.

\section{A COMPARISON OF PARTICLE SWARM OPTIMIZATION AND FIREFLY ALGORITHM}

In this section, we study performance of PSO and FA in estimating the parameters of the LotkaVolterra competition model. The Lotka-Volterra competition model could be represented as

$$
\begin{aligned}
& \frac{d y_{1}}{d t}=r_{1} y_{1}\left(1-\frac{y_{1}}{K_{1}}\right)-b_{1} y_{1} y_{2}, \\
& \frac{d y_{2}}{d t}=r_{2} y_{2}\left(1-\frac{y_{2}}{K_{2}}\right)-b_{2} y_{1} y_{2} .
\end{aligned}
$$


Fatmawati et al. applied the model to describe the competition between commercial banks and rural banks in Indonesia. Here $y_{1}(t)$ and $y_{2}(t)$ are annual profit of commercial bank and rural bank in Indonesia at $t$ year. Parameters $r_{1}$ and $r_{2}$ are annual profit growth rate, while $K_{1}$ and $K_{2}$ are maximum profit of commercial bank and rural bank respectively. Parameters $b_{1}$ and $b_{2}$ are reduction rate of the annual profit of the banks due to competition.

We apply PSO and FA to estimate parameters of the competition model by using annual profit of commercial bank and rural bank in Indonesia from $2004(\mathrm{t}=0)$ until $2018(\mathrm{t}=14)$. Here the profit unit is in billion rupiah. The annual profit data is cited from the Indonesia Banking Statistic data [20]. The annual profit data dynamics of commercial bank and rural bank are presented in the Table 1.

TABLE 1. Annual profit (in billion IDR) of commercial bank and rural bank.

\begin{tabular}{llll}
$\mathrm{t}$ & Year & $\mathrm{y} 1$ & $\mathrm{y} 2$ \\
\hline 0 & 2004 & 29463 & 539 \\
1 & 2005 & 24899 & 604 \\
2 & 2006 & 28334 & 509 \\
3 & 2007 & 35015 & 663 \\
4 & 2008 & 30606 & 849 \\
5 & 2009 & 45215 & 1158 \\
6 & 2010 & 57309 & 1447 \\
7 & 2011 & 75077 & 1853 \\
8 & 2012 & 92830 & 2328 \\
9 & 2013 & 106707 & 2661 \\
10 & 2014 & 112160 & 2682 \\
11 & 2015 & 104628 & 2755 \\
12 & 2016 & 106544 & 2936 \\
13 & 2017 & 131156 & 3210 \\
14 & 2018 & 150013 & 3371 \\
\hline
\end{tabular}

We estimated parameters in the Lotka-Volterra competition model such that the mean absolute percentage error (MAPE)

$$
M A P E=\frac{1}{2 n} \sum_{i=1}^{n}\left(\left|\frac{y_{1 i}-\widehat{y_{1} l}}{y_{1 i}}\right|+\left|\frac{y_{2 i}-\widehat{y_{2 l}}}{y_{2 i}}\right|\right)
$$

is minimum. Here $\mathrm{n}$ is number of observation data.

Table 2 presents performance comparison of Firefly Algorithm and the Particle Swarm Optimization (PSO) from 20 trials. Both algorithms are stopped after 200 iterations.

TABLE 2. Statistics of MAPE from 20 trials.

\begin{tabular}{lll} 
Statistics & FA & PSO \\
\hline Minimum (the best results) & 0.1429895 & 0.144149 \\
Mean & $0.1429920^{\mathrm{a}}$ & $0.148925^{\mathrm{b}}$ \\
Standard deviation & $0.0000049^{\mathrm{a}}$ & $0.001895^{\mathrm{b}}$ \\
Maximum & 0.1430123 & 0.151836 \\
\hline \multicolumn{2}{c}{ a,b different superscripts showed significant } \\
\multicolumn{2}{l}{ difference between group at the level 0.05.}
\end{tabular}

From the Table 2, we found that the MAPE average of firefly algorithm was little bit smaller than the MAPE average of particle swarm optimization. We also found that MAPE variance of firefly algorithm was much smaller than MAPE variance of particle swarm optimization. Hence the firefly algorithm is more robust the the particle swarm optimization method. This results indicate that for parameter estimation of Lotka-Volterra competition model, firefly algorithm is more beneficial than the particle swarm optimization method.

\section{CONCLUSIONS}

We have compared performance of particle swarm optimization and firefly algorithm to estimate parameters from Lotka-Volterra competition model. We found that both algorithms could be applied to estimate parameters of the 
Lotka-Volterra competition mathematical model. We found that the firefly algorithm is more beneficial than the particle swarm optimization, since the firefly algorithm gives a smaller error and smaller variance than the particle swarm optimization method.

\section{ACKNOWLEDGMENTS}

The authors would like thank to the Ministry of Research, Technology, and Higher Education Republic of Indonesia for supporting this research.

\section{REFERENCES}

1. Haupt, R. L. \& Haupt, S. E., Practical genetic algorithms, 2nd ed., John Wiley \& Sons, 10-13 (2004).

2. Windarto, Indratno, S. W., Nuraini, N., \& Soewono, E., A comparison of binary and continuous genetic algorithm in parameter estimation of a logistic growth model, AIP Conference Proceedings 1587, 139142 (2014).

3. Windarto, Eridani \& Purwati, U.D., A Comparison of Continuous Genetic Algorithm and Particle Swarm Optimization in Parameter Estimation of Gompertz Growth Model, AIP Conference Proceedings 2084, 020017 (2019).

4. Giuffrida, A., Ziino, G., Valenti, D., Donato, G., \& Panebianco, A., Application of an interspecific competi- tion model to predict the growth of Aeromonas hydrophila on fish surfaces during the refrigerated storage, Archiv fr lebensmittelhygiene 58(4), (2008).

5. Lee, S., Lee, D., Oh, H., Technological forecasting at the Korean stock market: A dynamic competition analysis using LotkaVolterra model, Technological Forecasting and Social Change Change 72(8), 1044-1057 (2005).

6. Hung, H., Tsai, Y., \& Wu, M., A modified LotkaVolterra model for competition forecasting in Taiwans retail industry, Computers \& Industrial Engineering 77, 7079 (2014).

7. Hung, H., Chiu, Y., Huang, H., \& Wu, M., An enhanced application of LotkaVolterra model to forecast the sales of two competing retail formats, Computers \& Industrial Engineering 109, 325334 (2017).

8. Fatmawati, Khan, M.A., Azizah, M., Windarto, \& Ullah, S., A fractional model for the dynamics of compe- tition between commercial and rural banks in Indonesia, Chaos, Solitons and Fractals 122, 3246 (2019).

9. Koay, C.A. \& Srinivasan, D., Particle swarm optimization-based approach for generator maintenance scheduling. In: Proceedings of the 2003 IEEE swarm intelligence symposium, 167173 (2003).

10. Weijun, X., Zhiming, W., Wei, Z. \& Genke, Y., A new hybrid optimization algorithm for the job-shop scheduling problem, Proceedings of the 2004 American Control Conference, 55525557 (2004).

11. Wang, K.P., Huang, L., Zhou, C.G. \& Pang,W., Particle swarm optimization for traveling salesman problem, 2003 International Conference on Machine Learning and Cybernetics, 15831585 (2003).

12. Liao, C. J., Chao-Tang Tseng, Luarn, P., A discrete version of particle swarm optimization for flowshop scheduling problems, Computers and Operations Research Vol. 34, No. 10, pp. 3099-3111 (2017).

13. Wu, B., Yanwei, Z., Yaliang, M., Hongzhao, D. \& Weian,W., Particle swarm optimization method for vehicle routing problem, Fifth World Congress on Intelligent Control and Automation, 22192221 (2004).

14. Mahanta, G.B., Rout, A., Deepak, B.B.V.L., \& Biswal, B.B., Application of meta-heuristic optimization techniques for design optimization of a robotic gripper , International Journal of Applied Metaheuristic Computing 10(3), 107-133 (2019).

15. Panigrahi, T.K., Mishra, D.K., Pati, S.S., \& Mohanty, A., A contribution to modelling and study of SSSC compensator employing firefly algorithm, International Journal of Innovative Technology and Exploring Engineering 8(7), 569-573 (2019).

16. Hang, D., Li, X., Application of Improved Particle Swarm Optimization Algorithm Based on GSO in Optimization Design of FIR Digital Filter, Proceedings of 2018 IEEE International Conference of Safety Produce Informatization, IICSPI 201812 April 2019, 8690503, pp. $84-87$ (2019).

17. Palmieri, N., Yang, X.-S., De Rango, F., \& Marano, S., Comparison of bio-inspired algorithms applied to the coordination of mobile robots considering the energy consumption, Neural Computing and Applications 31(1), 263-286 (2019).

18. Hussain, M., \& Jenkins, W.K., Effectiveness of the bio-inspired firefly algorithm in adaptive signal processing for nonlinear systems, Proceedings - IEEE International Symposium on Circuits and Systems Vol. 2019, 87020832019 (2019).

19. Farzana, D.F., \& Mahadevan, K., Performance comparison using firefly and PSO algorithms on congestion 
management of deregulated power market involving renewable energy sources, Soft Computing (2019).

20. Otoritas Jasa Keuangan, Statistik Perbankan Indonesia 2004-2018, http://www.ojk.go.id/data-statistikperbankan-indonesia [Accessed on 28 July 2019]. 


\section{Endpoint Protection Guide}

Uncover the 5 critical elements your next endpoint security solution needs.

\section{AIP Conference Proceedings}

COUNTRY

United States

Universities and research institutions in United States
SUBJECT AREA AND CATEGORY

Physics and Astronomy

Physics and Astronomy

(miscellaneous)
PUBLISHER

H-INDEX

American

Institute of

Physics
75

(i) $X$

Scopus

Indexed Journal

Call for Papers

August Issue

Fast Track Peer

Reviewed Publication.

tojqi.net 


\section{Scopus Indexed J}

Call for Papers August I

Fast Track Peer Reviewed P

tojqi.net

SCOPE

Today, AIP Conference Proceedings contain over 100,000 articles published in 1700+ proceedings and is growing by 100 volumes every year. This substantial body of scientific literature is testament to our 40-year history as a world-class publishing partner, recognized internationally and trusted by conference organizers worldwide. Whether you are planning a small specialist workshop or organizing the largest international conference, contact us, or read these testimonials, to find out why so many organizers publish with AIP Conference Proceedings.

\section{International Conference 2021}
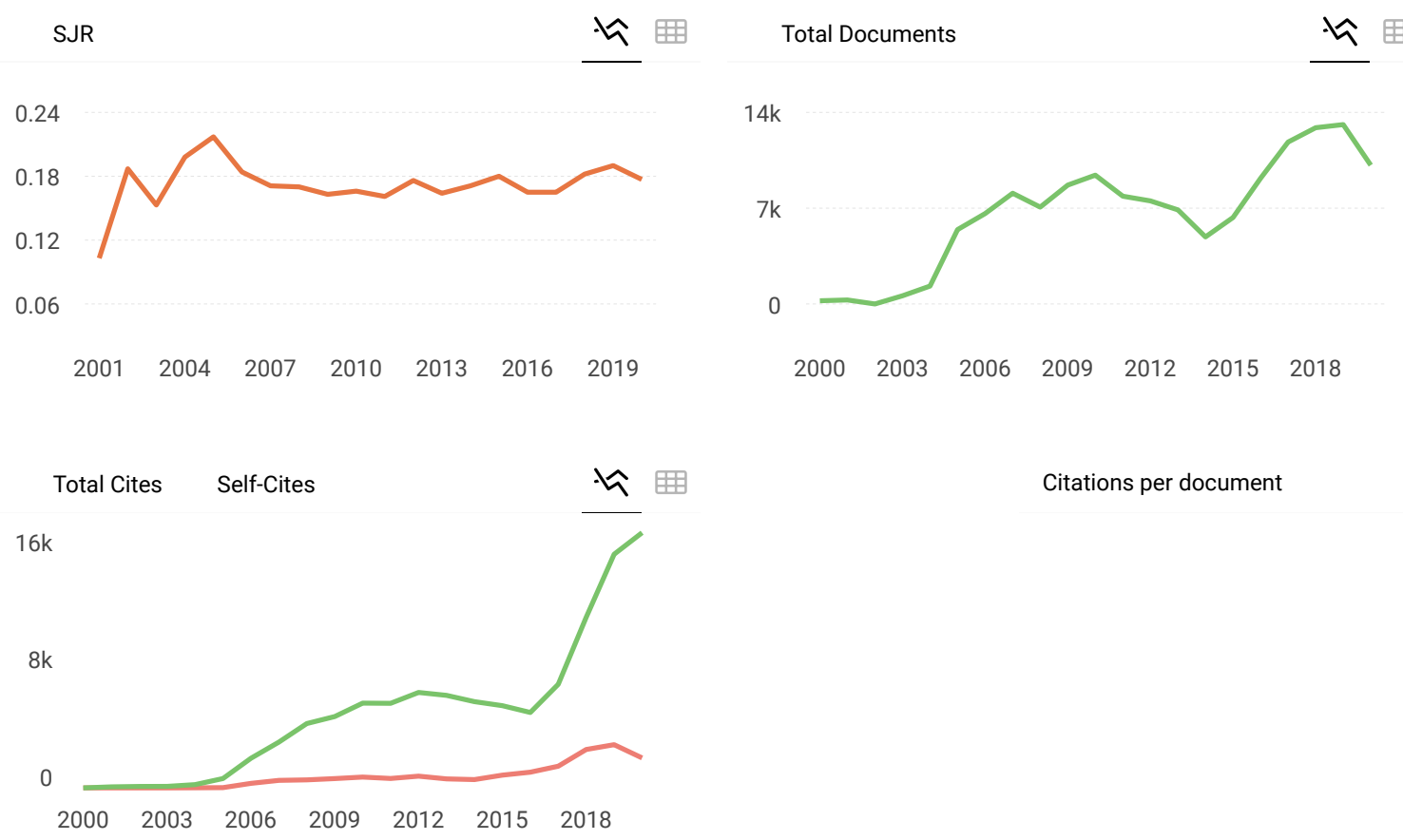

Citations per document 

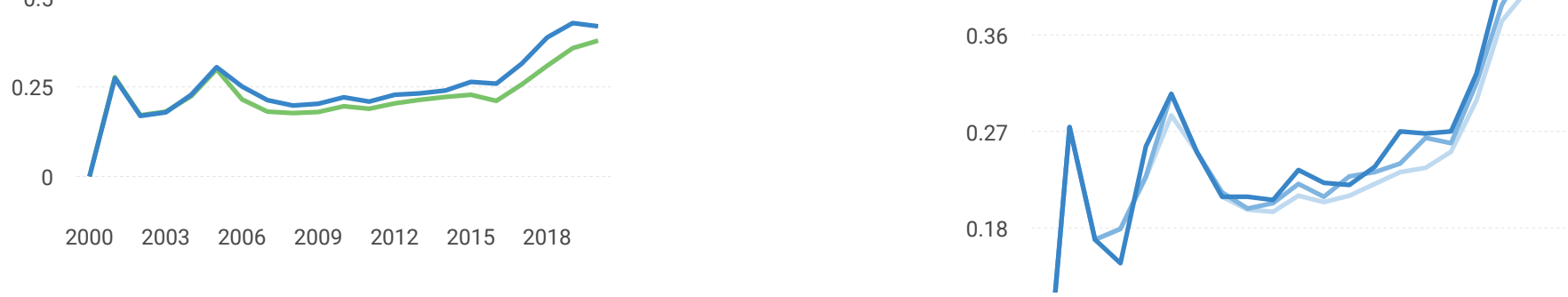

\% International Collaboration
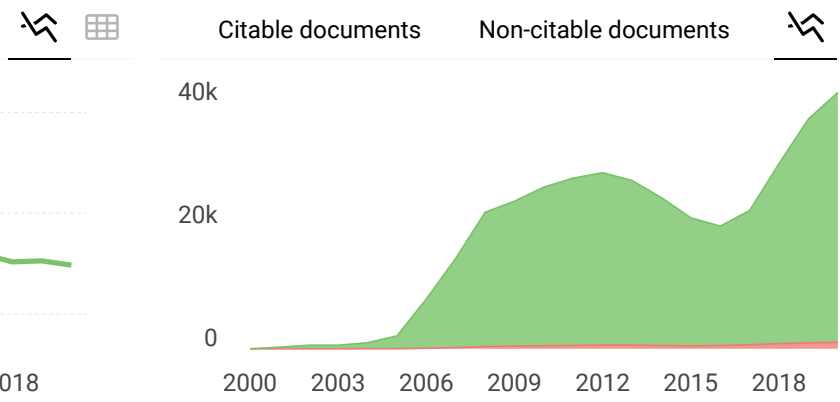

40

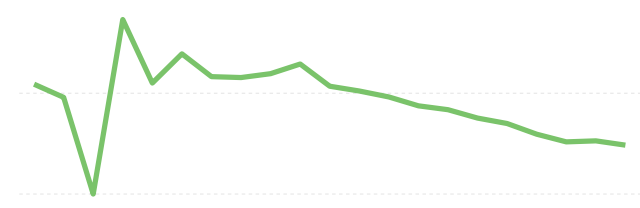

$\begin{array}{lllllll}2000 & 2003 & 2006 & 2009 & 2012 & 2015 & 2018\end{array}$

$\begin{array}{lllllll}2000 & 2003 & 2006 & 2009 & 2012 & 2015 & 2018\end{array}$

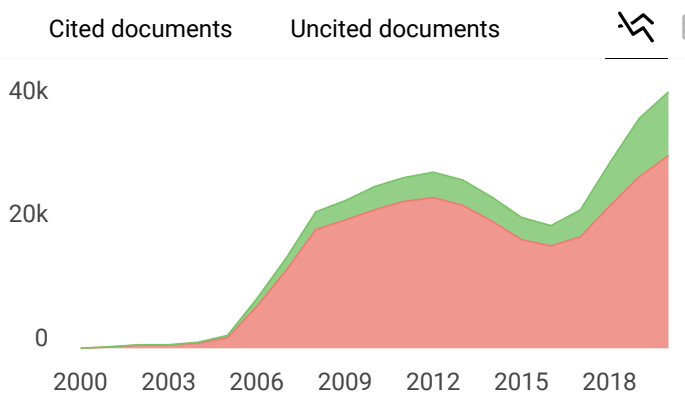

\begin{tabular}{|l|l|}
\hline AlP Conference Proceedings & $\begin{array}{l}\text { Show this widget in } \\
\text { your own website }\end{array}$ \\
\begin{tabular}{|l|l|} 
Not yet assigned \\
quartile
\end{tabular} & $\begin{array}{l}\text { Just copy the code below } \\
\text { and paste within your html } \\
\text { code: }\end{array}$ \\
\hline $\begin{array}{l}\text { SJR } 2020 \\
0.18\end{array}$ & <a href="https://www.scima? \\
\hline powered by scimagojr.com
\end{tabular}

\section{G SCImago Graphica}

Explore, visually communicate and make sense of data with our new free tool.

Get it

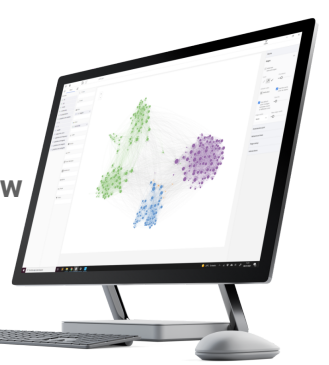

Metrics based on Scopus $\AA$ data as of April 2021

\section{Dr Kumutha D 2 weeks ago}

Dear Sir,

Greetings!!!

What is the Q value? Because, in our institution Q1, Q2, Q3 is very much necessary...

Through conference i planned to submit a paper... Please let me know 
Melanie Ortiz 2 weeks ago

Dear Dr Kumutha,

Thank you for contacting us. Please see comments below.

Best regards, SCImago Team

Fathi awad 4 weeks ago

$\mathrm{Hi}$

I am asking about the Q factor for AIP proceedings.

Thank you very much

reply

Melanie Ortiz 3 weeks ago

Dear Fathi,

Thank you for contacting us. Please see comments below.

Best Regards, SCImago Team

Ghazwan Jreou 2 months ago

Dear sir

respects

would you please let me know in which $Q$ is your journal (conferences and proceeding) classified? according to Scopus $\mathrm{Q}$ classification list.

with regards.

reply

Melanie Ortiz 2 months ago

SCImago Team

Dear Ghazwan,

Thank you for contacting us. We calculate the SJR data for all the publication's types, but the Quartile's data are only calculated for Journals and Book Series.

Best regards, SCImago Team 
reply

Melanie Ortiz 4 months ago

Dear Ashok,

Thank you very much for your comment.

All the metadata have been provided by Scopus /Elsevier in their last update sent to

SCImago, including the Coverage's period data. The SJR for 2019 was released on 11

June 2020. Therefore, the indicators for 2020 will be available in June 2021.

We suggest you consult the Scopus database directly to see the current index status as

SJR is a static image of Scopus, which is changing every day.

Best Regards, SCImago Team

Kay 7 months ago

My university is going to organise a conference in social science on 27-28 Oct 2021. We would like to publish our conference papers in your proceeding as our official proceeding. What are the procedures and publication fees?

Regards.

reply

Melanie Ortiz 7 months ago

Dear Kay,

thank you for contacting us.

We are sorry to tell you that SCImago Journal \& Country Rank is not a publication. SJR is a portal with scientometric indicators of journals indexed in Elsevier/Scopus.

Unfortunately, we cannot help you with your request, we suggest you visit the homepage or contact the editorial staff, so they could inform you more deeply.

Best Regards, SCImago Team

R Ruslan 8 months ago

I have published articles on AIP, but until now I have not received confirmation for my Scopus ID, please explain. thank you

reply

Melanie Ortiz 8 months ago

Dear Ruslan,

thank you very much for your comment, unfortunately we cannot help you with your request. We suggest you contact Scopus support: 
Vikas 11 months ago

currently, the journal is not assigned quartile ( $Q$ indexing). When we can expect the assignment.

reply

\section{Melanie Ortiz 11 months ago}

Dear Vikas,

Thank you for contacting us. We calculate the SJR data for all the publication's types, but the Quartile's data are only calculated for Journals and Book Series.

Best regards, SCImago Team

\section{S Siddik 1 year ago}

This will come under scopus journal list?

reply

\section{Melanie Ortiz 1 year ago}

Dear Siddik,

Thank you very much for your comment.

All the metadata have been provided by Scopus /Elsevier in their last update sent to SCImago, including the Coverage's period data. The SJR for 2019 was updated on June 2020,11 . We suggest you consult the Scopus database directly to see the current index status as SJR is a static image of Scopus, which is changing every day.

Best Regards, SCImago Team

\section{H Hassan Yassein 1 year ago}

ISSN of this journal different of ISSN in Scopus, although the data of

SJR depends on the scopes

reply

\section{Melanie Ortiz 1 year ago}

Dear Hassan,

Thank you for contacting us.

SJR is a portal with scientometric indicators of journals indexed in Scopus. All the data (Title, ISSN, etc.) have been provided by Scopus /Elsevier and SCImago doesn't have the authority over this data which are property of Scopus/Elsevier. SCImago has a signed 
agreement that limits our performance to the generation of scientometric indicators derived from the metadata sent in the last update (April/May 2020).

The next SCImago update will be made throughout June 2020 with the new update sent by Scopus. We suggest you wait for that date in order to see if there are any changes regarding this matter.

Best Regards, SCImago Team

Khairil 1 year ago

Is this proceeding ranked Q4?

reply

\section{A ali mohammed 1 year ago}

why this journal dont have any rank yet?

it is dont belong to $\mathrm{Q} 1,2,3,4$ ?

reply

Melanie Ortiz 1 year ago

Dear Ali,

Thank you for contacting us. We calculate the SJR data for all the publication types, but the Quartile data are only calculated for Journal type's publications. Best regards,

SCImago Team

\section{A Akshya Sekar 1 year ago}

$\mathrm{Hi} \mathrm{mam} / \mathrm{sir}$,

I want to know whether this AIP conference proceeding is indexed in $\mathrm{SCl}$ or not?

Thanks

reply

Melanie Ortiz 1 year ago

Dear Akshya,

Thank you for contacting us. SJR is a portal with scientometric indicators of journals indexed in Elsevier/Scopus. Unfortunately, we cannot help you with your request referring the index status. We suggest you to consult Scopus database (see the current status of the journal) or other databases (like WoS). Best Regards, SCImago Team 
Khairil 2 years ago

Your IP (036.071.233.236) is blocked.

Block Reason: This IP was identified as infiltrated and is being used by sci-hub as a proxy.

How to unblock this my IP for acess AIP site?

thanks

reply

Melanie Ortiz 2 years ago

SCImago Team

Dear Khairil,

thank you for contacting us.

Sorry to tell you that SCImago Journal \& Country Rank is not a journal. SJR is a portal with scientometric indicators of journals indexed in Elsevier/Scopus.

Unfortunately, we cannot help you with your request, we suggest you to contact the

journal's editorial staff by e-mail. Best Regards, SCImago Team

Duha Ahmed 2 years ago

dear Admin

about the AIP Conference Proceeding can you see the Scopus site because the date end to 2019 is there any update about this time or change it to 2020 in the near future and you will see it in the site of Scopus

https://www.scopus.com/sourceid/26916

I hope the AIP Conference Proceeding is still in the Scopus for 2020

with my best wishes

Miss Duha

reply

Melanie Ortiz 2 years ago

Dear Duha,

Thank you for contacting us. Unfortunately, we cannot see what will happen in the future with this journal. Best Regards, SCImago Team

M mohammed 2 years ago

Is the (AIP Conference Proceeding ) out of Scopes because I tried to search for it in Scopes and I did not find it

Please answer me

reply 
Melanie Ortiz 2 years ago

Dear Mohammed,

thank you for contacting us. You can find it in Scopus:

https://www.scopus.com/sourceid/26916

Best Regards, SCImago Team

Thanh Quang Khai Lam 2 years ago

Dear Elena Corera!

Can you tell me "Lecture notes in civil engineering" in Q4?

i don't see in Scimago.

Thank you

reply

Melanie Ortiz 2 years ago

SCImago Team

Dear Thanh,

Thank you for contacting us. We calculate the SJR data for all the publication types, but the Quartile data are only calculated for Journal type's publications. Best regards,

SCImago Team

Teo Jin Chuan 2 years ago

Dear Admin,

Can i know is this journal Q1,Q2,Q3 or Q4. Thank you.

Regards

reply

Melanie Ortiz 2 years ago

Dear Teo, thank you very much for your request. You can consult that information in SJR website. Best Regards, SCImago Team

H Hassan Abdulhadi 3 years ago

I ASKE ABOUT AIP CONFERENCE PROCEEDINGS WITHIN SCOPUS OR THOMSON REUTERS WITH BEST WISHES

reply 
I ASKE ABOUT AIP CONFERENCE PROCEEDINGS WITHIN SCOPUS OR THOMSON REUTERS WITH BEST WISHES

Elena Corera 3 years ago

Dear Hassan,

thank you for your request, all the journals included in SJR are indexed in Scopus. Elsevier / Scopus is our data provider.

Best Regards,

SCImago Team

\section{Tarik 3 years ago}

Dear. Elena

$\mathrm{Hi}$

Please can we concedar AIP conference proceeding as journal. What i mean ,the publication type could be

journal of AIP conference proceedings .

Best regards

TArik AlOmran

reply

Elena Corera 3 years ago

Dear Tarik

thank you very much for your comment. Unfortunately, we cannot help you with your request, we suggest you contact journal's editorial staff so they could inform you more deeply. You can find contact information in SJR website https://www.scimagojr.com

Best regards,

SCImago Team

Dunia 3 years ago

dear

did the AIP conference (TMREES 18)have Thomson roeters or scopus or SJR Rank or not?

reply 
Dear Dunia,

thank you very much for your comment. SCImago Journal \& Country Ranks shows all the journal's vailable information in Open Access If you do not locate the journal in the search engine, Scopus / Elsevier has not provided us those data.

Best Regards,

SCImago Tea

\section{B Budi Adiperdana 3 years ago}

Dear Admin,

Could you please add the Quartile Rank for AIP Conference Proceedings

Best regards,

Budi

reply

Elena Corera 3 years ago

Dear Budi, for Conferences and Proceedings the SJR is not calculated. Best Regards, SCImago Team

\section{Leave a comment}

\section{Name}

Email

(will not be published)

I'm not a robot 
The users of Scimago Journal \& Country Rank have the possibility to dialogue through comments linked to a specific journal. The purpose is to have a forum in which general doubts about the processes of publication in the journal, experiences and other issues derived from the publication of papers are resolved. For topics on particular articles, maintain the dialogue through the usual channels with your editor.

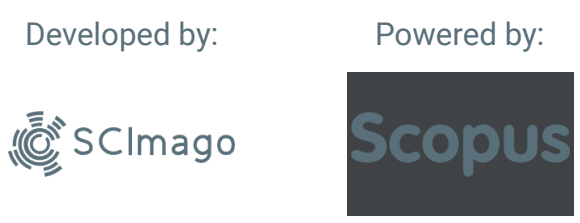

Follow us on @ScimagoJR

Scimago Lab, Copyright 2007-2020. Data Source: Scopus ${ }^{\circledR}$ 